离子自絡合阴离子中圈換出原子序小的、絡合能力弱 的希土: $\left[\operatorname{Ln}_{A} \mathrm{Y}\right]^{-}+\operatorname{Ln}_{A}^{3+} \longrightarrow \operatorname{Ln}_{A}{ }^{3+}+\left[\operatorname{Ln}_{B} \mathrm{Y}\right]^{-} \mathrm{Y}-$ 絡合剂。当存有阳离子交換树脂或沉淀剂时垖可达到 分离的目的。（4）在有絡合剂存在时可强化分級結晶 法，如有氨基三醋酸、醋酸銨等絡合剂存在时，可減 少分級結晶的次数。

鈰自三价氧化成四价后生成絡合物的能力大大提 高, 已如前述, 可利用四价鈰的这一特性来分离鈰。分 离的方法有如: (1) 溶剂萃取法, 利用四价鋪在硝酸溶 液中成絡合酸 $\mathrm{H}_{2}\left[\mathrm{Ce}\left(\mathrm{NO}_{3}\right)_{6}\right]$ 而可被乙醚、磷酸三丁酯、 乙酸乙酯、乙酸丁酯、硝基甲烷等有机溶剂所萃取。

(2)硝酸鈰銨結晶法,利用四价鈰与碑酸銨生成于浓硝 酸中溶解度小的硝酸鈰銨絡盐結晶 $\left(\mathrm{NH}_{4}\right)_{2} \mathrm{Ce}\left(\mathrm{NO}_{3}\right)_{6}$, 且晶型不同于易溶于浓硝酸中的其他希土的硝酸銨复 盐, 因而可用結晶法使之分窝。(3) 利用四价蹄与飽 和草酸銨生成可溶性絡合物 $\left(\mathrm{NH}_{4}\right)_{2}\left[\mathrm{Ce}\left(\mathrm{C}_{2} \mathrm{O}_{4}\right)_{3}\right]$ 而其
他三价希土生成草酸盐沉淀而使之分离等方法。

由此可見，希土絡合物在分离上的应用是很广泛 的，因此，大力开展希土絡合物的制备，㸴究其組成 及性稹，研究其生成条件、存在范围和稳定性- 这对 寻找新的及改进現有的分离方法都是很有意义的。

从上述可見，当人們握掌了希士元素的一些性稹 的规律，抹从而运用这些规律在分离上以后，目前已 能成功地解决希土元素的分离問題。

随着人們对希土元素研究的深入，在积累了更大 量的有关希土元素性稹的資料和数据以后，将会发現 更多的規律，使能更有效地解决希土的分析、分离、 生产与应用等問題。

解放十年来，在党的領导下，我国在希士元素方 面也进行了大量的研究工作，在利用上逝各种性稹的 分离方法的研究中，都有一定的成就和貢献，在希土 元素的領域队現正为赶上国际先进水平而努力。

\title{
在控制植物生长与发育中一些化学的 与物理的处理的作用
}

婁 成 后

\section{农业生产中控制植物生长与 发育的重要性}

一般說来,农业生产比起工业生产来要复杂得多。 这主要是因为农业生产是在大面积的复杂士壤 結 构 中，在变化多端的气候条件下进行的，需要长时期的 橙营才能得到收获。各种条件在空間上与时間上稳有 配合不当，就会影响到产量与收成，植物的一生郎是 制造食物的工場及是生产的对象。对大田作物来說，或 片的作物 (垶体) 要在前期尽量地发展它們的地上的与 地下的营养面积，充分地利用大气与土壤所供应的营 养条件，后期則用之来供应生殖器管的形成。同时它 們还要能够保持其在大由中結构的稳定，不致因风、 雨、旱、涝、病虫、杂草等自然災害而受到破坏，从而 保証产品的最后丰收。由此看来，农业生产中所出現 的問題必然是錯綜复杂与相互关連的，需要因时因 地，随机应变地采取适当的綜合措施加以解决。我国 农业大跃进的丰产經驗中充分地显示出毛主席所提出
的八字宪法的威力。其中水，肥，土的人工經营供給 了优越的土壤营养条件，保䃌了作物的“根深叶茂”, 再配合上良种和密植，适当的管理与保护，达到了营 养面积的及时展开，与繁殖器官的最后优势，

实际上，栽培的作物，和飼养的家禽与星殖的土 壤一样，乃是自然界的素材长期經过人类加工的产 物，只有在人們的經常照頋下，作物才能恰如人意的 生长发育，使得某些有經济价值的部位特別发达。然 而一旦脫离人們的照管，它就不会有高的經济产量， 谌至很难生侾下去。植物的生长与发育和各种的营养 条件是相互影响与相互制約的。一方面，作物的生长 与发育有赖于各种营养的供应。田間措施着重在利用 灌溉，施肥，耕种……等改善土壤营养的条件来控制 作物生长与发育。不合理的灌泊，施肥就会召致作物 生长发育的不正常，引起徒长，倒伏，器官的脫落， 产量的降低等。另一方面，营养条件的利用与营养物 稹的分配却又取决于作物生长发育的进程。例如說， 份在休眠而未能发芽的种子郎或有优良的营养条件也 
完全不能利用，又如，植物的一生中，經常出現新老 部位的更替,营养物稹的重新分配与再度利用。种子的 萌发导致植株的成长，而枝叶的黄菜又件随着种子的 形成。每当作物的生殖体出現以后，植物体內的各种 营养的轉变与运輸比起营养体的生长来, 可以有极其 显著的不同。此外，近年来总結农民丰产經驗中显示 出单位面积的高額丰产不仅要燕成片作物的生长茂盛 而且更要靠植㭠的各部位間（生殖体与营养体，地上 部分与地下部分, 主千与分支等) 生长发育的协調得 宜。这种生长上的相百关系(相关性)若是在不合理农 的业措施中或是不良的气候条件下不能維持适当的协 調时, 就会引起某些部位的过分发达因而造成整个植 株在結构上的不稳定，不但容易受到自然災害的侵袭 抹且威胁到最終的产量。在一次开花的粮食作物中、 这些相互关系的維持已約略如上所述; 而在多次开花 的植物如棉花中，情况就更为复杂些。这乃是由于棉 花的营养体与生殖体可以同时滋长与长期抹存。外界 条件稍有不当而引起生长相关性的失調时，或是訆营 养体居优势出現了枝叶徒长与霄鈴的脫落, 或是使生 殖体占上风，引起植株的“脫力”早衰。这种偏向一旦 发生还有自己促进, 变本加厉的趋势。棉株枝叶的过 分茂盛、过早的郁閉促使鳌鈴脫落, 而蕾鈴脫落, 轉过 来更加强了营养体的徒长; 反之，植株棉鈴負担过多 对营养体生长有显著的抑制，对根系的食料供应也沓 著降低。根系活动因缺乏食物而減低，更加抑制了枝 叶的生长。因此生长相关性的㟻时失調，若不郎早加 以紏正，可以引起一系列的不良后果。我国植棉的劳 模都善于查形覌色師早地看苗头, 防思于未燃, 在这方 面累积了丰富的經驗。一着失錯影响全局，因之，除了 通过灌激，施肥，耕耘等改良土壤营养来控制作物的 生长发育的措施以外，生产中还迫切地需要更为直接 而有效的控制方法。在我国优秀的农业传統中，已絓 发展出来多种控制植物生长发育的有效措施, 如修 学, 切割, 整枝, 未叶，摘心、斬根，嫁接以至播前 的种子处理与播后的果实催熟等方法，至今还作为农 业生产措施中的重要环苦在广泛地运用着与发展着。

\section{化学与物理的处理发展的情况}

植物发育生理比起植物营养生理来較为复杂，它 的进展也比較迟緩, 但是近 $20-30$ 年来在这方面却有 很大的进步。現代植物发育生理的知識比較完整与有 系統地总結在李森科的阶段发育学說中, 从之可以看 到植物的个体发育不是单純受一般营养条件所支配的 过程, 而是受許多因素的影响抹且随植侏的成长, 按步
就班地来进行的复杂程序。植物的生长发有有其阶段 性。李森科指出植物个体发育的各个阶段所需要的外 界条件与訪植物在原产地物种形成中所經历的遭遇是 一致的。了解到植物在不同发有阶段对外界条件的特 殊要求，我們就可以人为地在适当的条件下对一些荫 发的种子(如冬小麦) 給以一段时期的低溫, 当某些植 物 (如菊花) 成长时, 人为地楦短日照时数。这样改变 溫度与光照就可以对植物发育的进程任意加以控制。

把才萌发的种子作脫水或盐水的处理，来进行对 小麦等作物抗早或抗盐的“鍛炼”，也是根据阶段发青 学說中有机体愈是在发有早期愈容易感受外界的变化 而对之发生适应这个原則而来。

植物中某些器官的形成或某些过程的出現，旧于 长期对生存条件的适应, 往往需要特殊的物理与化学 的条件。如有些对光敏感的烟草种子只有經过短期曝 光才能萌发, 許多冷敏的树种需要低溫的层积处理。 花生的果实只等鉆入土內在缺光的情形下，才能长 大，等等，我們用人工处理来供应这些条件就可催促 这些变化的进行。

有一些物理与化学的处理对植物的生长与发育过 程也，具有重大的影响与实践的意义，其中許多都是在 长期生产实践仙所摸索出来的㸃貴經驗。有些货环制, 摘第等手术，显然与营养物稹的分配与㳙耗有密切关 系; 但号一些处理的理論依楛份未得到定論。各种各 样的物理与化学因素，諸如普通的无机化合物，剧烈 的毒䒹，有机溶剂，氧化还原剂，溫度的变化，机械 的扰动，等等以及随着物稹科学的进展所发明創造的 各种型式的电流，各种波长的幅射，与一些复杂的生 物化学药剂等等, 都曾經用来作为影响植物生长发育 的因素。不同的处理在打破与延迟芽的休眠上，促进 插枝生根上，防止与促进器官脫落上，加速植株的生 长上，誘导开花結实上，都有肯定的影响抹找到了生 产中的应用。米丘林在他的时代曾注意到利用这种完 全新的因素在栽培里来影响植物的生活。他訓为这些 因素不属于任何无机与有机肥料而起着目前所謂的刺 激剂的作用。这类研究还在継續展开，方兴末艾*。

一般說来，許多物理化学因素在植物生长发育上 所引起的效应有下列的几个共同处:

（1）歌多性稹极不相同的物理化学因素可以在植 物体內引起同一的生理效应, 如无机与有机获涧，超

* 汒:比較強烈的化学与物理的处理, 如用水素等获剂处 理幼芽,或用电离幅射照射种一，可以收变有机体的海 传属性，从而也就影响了它的生长发育。在菌种与作 物的人工引变上已縕应用。 
声波，机硪处理都可以打破馬鈴薯块葽上芽的休眠。

（2）同一处理随其处理植株的种类，部位，发南 时期与生理状态的不同，可以对之发生多重的效 应， 也就是象生长素的花剂处理可以促进种子发芽，插枝 生根，花朵結实等多样的影响。

（3）对植物的一个部位来說，一种处理随其所用 剂量与浓度的不同，而有促进与抑制两种生理上相反 的效应。一般說，在低剂量下为促进而在略高剂量下 即轉为抑制。对动物来說，物理的与化学的刺激也随 剂量的增加而表現出这种两重性。

以上三点也是有机体在受到各种刺激时所表現出 来的特征, 因之这些处理的因素也就撤統地被称为植 物生长刺激剂。这些現象也令人想到它們是通过共同 的生理机制而达到的类似效果。不少工作者都䚯为它 們是通过对原生貭状态的影响而达到的。各种物理与 化学的处理（諸如，机械的震古，电流的通过，溫度 的改变，多种菞剂与植物組織提取液的处理）对敏感 組織說, 可以引起原生貭膜电位与电阻抗的临时下降; 对普通組織說，可以引起原生稹中結合态釷的释放与 粘度等的降低; 对幼嫩組織說，可以引起胞核的临时 解体。这些效应在低剂量下在某种程度上是可逆的， 在高剂量下或长期处理中，或是有机体对之发生調应 使得刺激不継續生效，或是它引起了永久性的伤 害, 使得机能衰退。然而把这些效应单純地䚯为是刺激的 作用是不能令人滿意的。刺激作用扭不能包括許多处 理的特殊效应。各种处理的物理化学因素有其特点,对 細胞的作用也不相同。它对細胞的特殊作用可能首先 导致上迅原生盾中的共同变化，因而时常会表現出相 同的效果。但是在有些特別是长期的生理效应中，許 多处理显然是大不相同的。例如高渗糖溶液最初施用 时也可以不起上述原生稹的变化，然而慢慢渗入細胞 內部可以作为細胞的食料。因此許多处理的特殊效应 的研究是从它們对于蛋白稹的結构, 酶的活性, 器官 机能的影响，以及对于內部成分与代謝途径的改变等 多方面来着手的。真正促进这类处理的研 究 蓬 勃 展 开，在理論与实践上相互为用，在应用上开辟了广闊 远景，可以說是由在植物体內含量很微而生理活性很 䖪的一些物稹的发現給推动起来的。

\section{植物体內生理活性物盾与 葋剂处理的关系}

目前已有許多試驗証明，植物的各个部位間在不 同的时期与条件下可以产生微量的特殊有机物貭，借 之可以影响其他部位的生长与发育，莸至为其他部位
生长发育所不可缺的。已經刵明，在植物幼嫩的生长 尖端可以产生生长素来促进下部的伸长，在家退的叶 子与成熟的果实中，产生乙烯可以促进其他果实的成 熟。果实与种子中时常有发芽的抑制剂，在走出休眠 时才逐漸消失，等等。根，荎、叶、花、果实中都各 有其特殊有机物的合成，固定根系不仅是水分矿稹的 吸收器官，也必需看作是特殊有机物合成上非常活跃 的器目，没有根系合成的有机物，地上部分的生长就 大为減弱終于停止。

在不同植株間，寄主与寄生物之間也时常靠一些 微量活跃物貭的分泌来达到相互影响的效应。赤菌 JF是以它的分泌物赤霖素来促进寄主水稻的 恶性 徒 长，寄生物往往靠寄主身上的“气息”来追踪 它的所 在，类似上述的例証还有很多，不胜枚举。

在植物生长相关性中起着“媒介”作用的一些有机 物稹，与大量的有机营养物稹如蛋白稹，糖、脂肪等 的不同处是它們的生理活性很强，在极微的剂量下由 这些部位轉移到其他部位，就会对后者的代謝过程与 生理活动有巨大的影响，虽然在植物体內还没有发現 象动物体中专門产生激素的腺体，这类物稹在植物体 內所起的作用却与动物的激素有非常相似处，因之； 世有人把其中的一些对植物生长发育有显著影响的物 貭，称为植物的生长激素。不少这类物稹已經从植物 体內分离与提淨出来，其化学結构已經鑑定清楚。其 中有的如生长素可以用人工合成，赤露素可以从真菌 的培养中大量提取。特別值得注意的是許多化学結构 与生长素类似的有机化合物, 如䒺乙酸，2.4一D 在生 理上也有类似甚至更为强烈的效应。在百万分之一到 千分之一的浓度，每亩由 0.1-100 克的用量下，就可 以对成片作物不同部位的生长发育产生促进或抑制的 作用。这些作用都在农业上已然找到了种种用途，药 剂的供应在工业上已然作到了廉价的大量供应。

由于生长素等对植物生长有非常活跃 的生 理 效 应,在資本主义国家中流行着一种学說,把生长素这类 物稹訪作是超乎有机体之上植物生命过程的专門控制 者。这种形而上学的解释給这方面工作的发展带来了 很大的障碍，因而遭到了苏联科学界应有的批評。这 些批評主要是針对着这种学說在覌点与方法論上的錯 誤而发生的，但持不策有些人故意曲解的那样，訆为 这些批評者反对这些生理活性物盾的存在以及研究它 們的可能性与必要性"。实际上,生长是个极其复杂的引

* 見論植物学杂志的不正确立場及其今后的工作，苏联 椬物学杂志, 1959 (2)。 
生理程序, 需要許多生理过程与很多物盾的参加, 缺 少了任何一个环节(如矿盾微量元素的缺泛)都会导致 生长的鲩滞。生长素这类生理活性物稹不过是許多生 理所需要物稹之一，而它本身又是植物体內的代謝产 物。

此外，这类生理活性物盾如赤露素，在不同程度 上可以代替許多冬性二年生作物在第一阶段所需要的 低溫与第二阶段所需要的长日照。这在控制这类植物 的发育上有很大的用处。但是必需指出这种代替讲不 意味着否定阶段发育的存在。阶段发育是建立在个体 发育是系統发育的延續以及生物与环境統一的原則上 的。它有着更为广闊的普通生物学的基础。而这个效 应正可以进一步說明在各个发育阶段內一系列的复杂 程序中，有赤電素所参与的代謝过程之存在。赤霉素 对促进个体发育随植物的种类而有很大的差別, 扭在 有些植物需要与一定的条件（如生长素、低温、或长 日照）合併处理才能发揮作用，也說明个体发育中代 謝过程的协調性扭不是单純靠特殊物稹所决定的。目 前已然在高等植物体中找到有类似赤霖素物 稹的存 在, 其物理化学性稹与生理效应与赤霖素极其 相 近, 而共含量随不同类型的植物、不同的生长条件与不同 的部位而有不同。植物对赤䨢素的反应差异很大，可 能与体內类似赤霹素及其他生长激素的美异有关。

然而, 也必須指出, 由于这类䓎剂的处理是外加 的影响，而所用剂量往往远远超过植物体内原有的含 量, 它所引起的效果有时是在天然生长情况下所不能 达到的。例如：用赤素处理过的甘篮抽出荅来可以 高达一文，单啡改善栽培条件就难于作到。又如：我 国的名贵䓎材黄蓮，野生性强，它的种子休眠期长， 萌发迟楥，通常要 1一2 年才能培育成苗，而用赤露 素，生长素，低温等抹用与直复的处理，2-3 月内 就可以培养成苗，从这两个例証里可見: 物理的与化 学的处理可以突破有机体固有的限制, 胜过自然, 垖 可扩展植物生长的幅度又可縮短生长的时間。

物理与化学处理的应用不仅在于其促进植物生长 与发育的方向。它們在抑制植物的生命活动以至毒害 植物生命上都非常有效。在这方面农业中也有广泛的 应用前途。像有些条菌剂就是由于微量的含銅或永等 的制剂对埧菌有致命的毒害而来。用紫外綫来灭菌消 专也根据同样道理。放射性同位素 $\mathrm{Co}^{60}$ 所放出的 輻射可以破坏长期館藏中馬鈴蕃的发育。在田間，庭 完，以及交通要道上利用化学䒜剂防除杂草是农䓎中 的后起之秀，发展得最块的部門之一。此外，在棉花 大豆等的机械化收割前利用化学药剂来脫掉叶子也正
在逐漸推厂应用。利用各种型式的䓎剂、电源、輻射 等来消除病虫害、杂草等对生产不利的生物因素, 看 来也是大有前途的。

\section{紜合措施中物理与化学的 处理的相互作用}

植物对蒌剂等处理的反应在不同場合下（如不同 种类，部位，发育时期，生理状况）极其不同，有时 选至相反。如同样的赤需素处理时常可以覌察到在早 期单独引起植株主䒱的伸长, 而晚期則促进了各个节 上腋芽分枝的蛮动。有时这类处理需要两种因素同时 抹用才能收效。如赤霰素必須与生长素併用才能促进 去了叶片的甘薯叶柄的伸长。还有試驗証明, 赤霰素对 所有的芽都有催促它們萌动的作用，而顶芽中的生长 素却有抑制下部腋芽萌发的相反效应，因之在不同时 期植物对赤霜素的反应不同，可能与其頂芽中生长的 优势与生长素的含量有关。从这些現象中可以看出: 植物各部位間的生长关柔不可能单裳一种調节物稹来 控制，而是由許多物盾参与的一些代謝过程相互作用 与相互制約的結果。

在利用䓎剂处理来控制植物的生长发育中，虽然 它可以誘导作物向有利于生产的方面发展, 促进了某 些部位的特別发达。然而䓎剂对植株的效应不是仅限 于一个部位而对其他部分毫无作用，不是只有着有利 的影响而没有不良的副作用。像 2.4-D 可以有效地制 止白荣的落叶，但同时使得荣叶受伤后容易筑烂。由 于这类处理对植物各部位生长关系原有的平衡有所改 变，其效果地必然不会限于一时一地，而会旁連到后 期与其他部位。由此看来，在这类处理中，必須配合 着一系列的綜合措施，作一些与副作用对抗的处理, 尽量取其所长, 补其所短, 才能收效。

在許多作物的赤需素处理中, 早期枝旪虽然茂盛, 但同时却削弱了根系的发育，晩期反而因之提早的衰 退。然而这个缺欠不是不可以預防与补䖝的。若适当 朵用处理的剂量, 抹增加肥料的施用与促进根系发达 的措施不使根系长期受到抑制，則枝叶的茂盛，从生 长的相关性来看，終归应該是对地下部分生长极为有 利的条件。一些試驗也确实证明是如此。

这类处理仅是农业生产中在适当条件下可以利用 来控制作物生长发有的有效措施之一。它必需与八字 宪法的各种条件密切配合才能发揮增加产量的作用。 把它当作万应如意的妙药而净指望着䓎到功成是不現 实的。这类处理的用处是在于改变作物生长发育的进 程，但絕不能用来代替植物生长所必需的各种营养条 
件。当受到处理的植株果实特別发达时，反而需要更 多的营养来配合这加速的进度。两者同时挷用才能相 当谷彰。当土壤与空气营养条件对作物协調的生长暫 时有不利的影响时，这类处理可以糾正这样的偏差。 如生长素可以防止番茄在冬季溫室栽培中 的落 花不 驾，及可減少气候不宜时的棉鈴脫落。然而长期的淹 洪，过久的郁閉，以及肥料的缺乏使得植物亏損，单 凭药剂处理，虽然能見效一时，終是无济于事。在番 茄、牧草、棉花等的这类处理中，时常見到由于营养 条件沟有配合得好，虽然早期的产量增加而晚期产量 反而減少。

\section{植物葯理学的开端}

植物体內許多生理活性物稹的发現以及人工合或 的植物生长刺激剂的应用, 标志着植物药理学的开端。 以往的农用䓎剂大都是外敷䓎，如杀菌的銅制剂，用 量很少、䓎效短暫、而且局限于在涂施的表面; 但是 生长刺激剂則属于內用获，可以被生活的植物吸收。

传鼬周身，用量少而收效久远。

䓎剂处理的应用时常是由于它对不同植物組織在 生理效应上的差异而来。在一定的剂量与植株的生长 情况下，菞剂对某一种植物 (杂草) 或植物的某一部分 (如生长錐) 比另一植物或另一部分的影响要 更为大 些，因而才能发揮它的調节作用。化学与物理的因素 对生活組織作用的差异又待徍建立在它的化学結构与 物理性稹 (如幅射的波长)的些微差异以及其对不同組 織的微妙关系上。正如这类处理用在医疗上一样，我 們略微改变药物的化学結构或用量, 或是改变輻射波 长与强度时，就可以改变它的生理作用与实际效果。 成百上干的新䓎在合成着与試用着，从之可以选择出 更为經济有效节省人工的措施来。

化学与物理的处理对作物不仅会起着有利的影 响，同时也会有不良的副作用。为了更好发揮其作用 与使用效率, 时常需要与其他处理扭用或与适当的营
养条件配合。处方用药因之姴結合实际情况取长补 短才能奏效，內用䒹剂首先影响正在生长的幼嫩 部 位，在体內可以长期有效，継續轉运，甚至遺留到下 代的种子去。有些內用药不仅植物对之非常敏感，处 理过植株的产品，被动物食用也会受到获害。因此在 使用这类药剂时必須特別当心，对药剂的特性与处理 的情况有相当的了解才能对症下药、灵活地加以运 用。

国内外关于这方面的研究发展得快。物理的处理 (超声波、原子能等) 除了設备在田間大量应用仍有不 便,大多数的应用仍是在室內处理种子、块等等延存器 官。化学䓎剂由于使用便利不仅用作种子处理, 在也 田間大量应用。在植物药理学的探討中，进展得最快 的是除菱剂与生长刺激剂，再次則是內用杀菌剂与除 虫剂。新除菱剂与除虫剂的探討多牛点化学的綜合与 飾选，而新生长刺激剂与杀菌剂除开化学綜合以外， 还从高等与低等植物的微量的生理活性 产品中去搜 寻。在理論上，一方面在探討䓎剂的化学結构与生理 效应的关系，用来指导效力更大新药剂的合成；另一 方面在研究这些获剂对各个部位成机能的影响以及追 究它对各种植物不同效应在生理上、形态上，以至生 长习性上的原因。

我国在解放初期还只有少数研究机关从事这方面 的工作，进展較緩，但是逐年发展特別是在大跃进中， 化学与物理的处理已形成为科学技术的辜众运动。各 地的試驗机关与工厂紛紛在制造这类药剂。全国各地 都有单位在进行生长素、赤霖素、超声波等农业应用 与生理效应的研究，其范围之广、面积之大，与进展 之速是空前末有，世所帘見的。

在多、快、好、省地建設社会主义中，为了要提 高产量与农业生产力抖与其他生产部門密切配合，最 新开辟的物理能源与大量合成的化学药剂必然会愈来 愈多地应用在植物生命活动的控制上，这是可以預期 的。 